\title{
Preuniversity science education in India: Insights and cross cultural comparison
}

\author{
K. K. Mashood ${ }^{1, *}$ and Vijay A. Singh ${ }^{2}$ \\ ${ }^{1}$ Homi Bhabha Centre for Science Education, Tata Institute of Fundamental Research, \\ Mumbai, 400 088, India \\ ${ }^{2} U M-D A E$ Centre for Excellence in Basic Sciences, Mumbai, 400 098, India
}

(Received 10 January 2019; published 18 March 2019)

\begin{abstract}
A large scale survey reveals that the performance of the Indian preuniversity students in internationally standardized physics tests is intermediate to the American and the Chinese but reveals a disturbing bimodality. Scientific reasoning skills, however, are similar to both. The bimodality in physics tests corresponds to two different educational experiences, one in which the school ties up with privately run coaching centers (which we term as the integrated mode) and the other (nonintegrated mode) which has no such arrangement. These two modes have an underlying economic connotation and pose equity concerns. The study draws attention to this problematic educational phenomenon, often called "shadow education," widely prevalent in many countries including India and China.
\end{abstract}

DOI: 10.1103/PhysRevPhysEducRes.15.013103

\section{INTRODUCTION}

The present study is concerned with aspects of preuniversity (grades 11 and 12) science education in India, which marks a watershed in the country's education system. It is motivated by an earlier work comparing the performance of American and Chinese students [1,2]. Our study is based on a systematic large scale survey using internationally standardized tests and permits a comparison of the performance of the Indian students in physics with the American and Chinese. It broadens the cross cultural perspective provided by Bao et al. whose study revealed that learning of content knowledge does not have an impact on the scientific reasoning ability of the students in the U.S. and China [1,2]. In addition, the study draws attention to the impact of a problematic educational phenomenon underlying the distribution of scores of Indian students. This phenomenon, often called "shadow education," has an economic underpinning and as such poses serious equity concerns. Our work also sheds light on the institutional structure and the nature of curriculum and instruction pertaining to preuniversity science education in India.

Preuniversity science education in India falls mainly under the purview of a national board, the Central Board of Secondary Education (CBSE). In addition, each state has its own board. Schools affiliated with CBSE follow a curriculum designed by the National Council of Education

"mashood@hbcse.tifr.res.in

Published by the American Physical Society under the terms of the Creative Commons Attribution 4.0 International license. Further distribution of this work must maintain attribution to the author(s) and the published article's title, journal citation, and DOI.
Research and Training (NCERT), which also serves as the basis for most of the state curricula. Physics is taught as part of a general science subject up to grade 10 . Thereafter, in grades 11 and 12 it is taught as a separate subject for students opting for the science stream as distinct from the commerce and the arts and humanities streams. Thus the Indian preuniversity education scenario shares elements of both the American and the Chinese systems. In terms of curricula, variety, and the two-year slot for physics it is similar to the U.S. Indeed the American introductory level text books are popular reference choices in grades 11 and 12 besides Indian textbooks [3-7]. The focus on problem solving driven by national admission tests is like the Chinese [1,2].

There exists another dimension to the Indian education scenario. Preuniversity education is heavily influenced by the highly competitive problem-solving based entrance examinations to engineering and medical courses taken at the end of grade 12. Admissions to institutes like the Indian Institutes of Technology (IITs) are viewed as stepping stones to successful careers globally [8-13]. The drive to qualify in competitive exams like the IIT Joint Entrance Examination (IIT JEE) has given rise to a parallel education system, also known as shadow education. Students attend school but also enroll in privately run coaching centers where detailed and intensive instruction is provided along with a heavy emphasis on problem solving. These private coaching centers are found in all parts of the country. The industry is estimated to have a turnover of 6.4 billion U.S. dollars per year [14]. They prospered in the backdrop of a lack of faith among parents in the traditional school system (established by the state in the last century) to prepare the students for competitive examinations. 
Over $95 \%$ of students we interviewed in our surveys over the past decade avail coaching [15-17]. Broadly, this is done in two modes. Students attend school and avail regular coaching in their free time. This we shall call the nonintegrated mode (NIM). On the other hand, the school ties up with a coaching center, thus catering to the dual requirements of qualifying in the state or national board and the competitive entrance tests. We shall designate this as the integrated mode (IM).

In NIM students must attend regular school but in their free time they can enroll in a coaching center of their choice. This free time is limited to the evenings or early mornings. The topics taught in school may not be in synchronization with the instruction in the coaching center, leaving the student to grapple with an overload. In IM, the school and the coaching class are virtually the same. All instruction is common and handled by the coaching class. The school plays a cosmetic role in terms of teaching subjects like English, regional languages, etc., which are not tested in the competitive exams. The IM is costlier, often with lucrative pay scales for teachers. Their fee is about 10 times the normal, which the majority cannot afford. The shadow education, however, has stressed the social system in many ways [14]. Despite this, IM schools are gaining in popularity by the day.

\section{ADMINISTRATION AND ANALYSIS}

Our sample comprised of preuniversity students from five distinct urban centers spread across the country. These centers were Jaipur (2), Patna (3), Mumbai (3), Hyderabad (2), and Bangalore (3). The number in brackets denotes the number of schools in each center. Over a million students from urban India appear each year for engineering entrance exams. Studies have shown that about $50 \%$ of students appearing for these exams come from 15 urban centers, which include those mentioned above [18]. The number of students in our sample was as large as 1118. All students were in the age range of 16 to 18 years. We ensured an equal distribution between NIM and IM students. The percentage of girls in both the groups was around $40 \%$. We administered three internationally standardized tests, the
Force Concept Inventory (FCI), the Conceptual Survey on Electricity and Magnetism (CSEM), and the Lawson's Classroom Test for Scientific Reasoning (LCTSR), in addition to the one on rotational kinematics developed by us $[16,17,19-23]$. These tests are recognized to be global benchmarks in the topics under consideration. We chose physics since it is considered paradigmatic in science education [1,2]. Our choices have the added advantage of facilitating an authentic cross cultural comparison, as these tests are the same as those used by Bao et al. except for the CSEM $[1,2,21]$. The CSEM was preferred over the Brief Electricity and Magnetism Assessment (BEMA) because the latter has more than 5 choices to some questions $[21,24]$. We found that students experience difficulties when the number of choices increase. In addition, for large samples statistical analyses are easier to accomplish if the number of choices to items is fixed. It may be noted that the subject content addressed by the BEMA and CSEM are similar. All schools were English medium. The tests were administered in English without any modifications. These were post-tests administered after the students had learned basic mechanics and electricity and magnetism. None of them had any explicit training in scientific reasoning. The instruction in all schools followed the traditional lecture method with the students sitting in multiple rows and teacher explaining the content with the help of a blackboard. Typical class size ranged from 30 to 40 students. Students were encouraged to answer all questions and no time limit was imposed. Students and teachers were not aware of the existence of concept inventories.

Table I gives the number of students, their average scores in percentage, along with the standard deviations in each of the tests. Each test was evaluated by giving 1 mark to the correct answer. There was no negative marking for wrong choices. As revealed by Table I the average of the Indian students in the FCI is intermediate to the American $(49.3 \pm 19.3)$ and the Chinese $(85.9 \pm 13.9)$ freshmen students [1,2]. A similar case is found with the CSEM score of Indian students when compared to the BEMA scores of the American $(26.6 \pm 10.0)$ and the Chinese $(65.6 \pm 12.8)$ students. It may be noted that students in all samples (American, Chinese, and Indian) underwent

TABLE I. The sample size $(N)$ and average scores in percentage of the U.S., Chinese, and Indian students along with the associated standard deviations, in the FCI, CSEM or BEMA, and LCSTR. For Indian students the data are first shown for the total sample, then separately for the NIM and the IM. Source of the data for the U.S. and China is the study by Bao et al. [1]. Note that for the U.S. and Chinese samples, BEMA was used instead of CSEM.

\begin{tabular}{lccccc}
\hline \hline & USA & China & India & NIM & IM \\
\hline$N$ (FCI) & 2681 & 523 & 1118 & 545 & 573 \\
Average score & $49.3 \pm 19.3$ & $85.9 \pm 13.9$ & $58.6 \pm 7.7$ & $38.1 \pm 7.5$ & $78.2 \pm 7.9$ \\
$N$ (CSEM or BEMA) & 650 & 331 & 554 & 271 & 283 \\
Average score & $26.6 \pm 10.0$ & $65.6 \pm 12.8$ & $46.2 \pm 10.4$ & $27.3 \pm 7.1$ & $64.22 \pm 9.8$ \\
$N$ (LCSTR) & 1061 & 370 & 403 & 196 & 207 \\
Average score & $74.2 \pm 18.0$ & $74.7 \pm 15.8$ & $69.3 \pm 5.6$ & $61.3 \pm 6.5$ & $77.1 \pm 3.9$ \\
\hline \hline
\end{tabular}




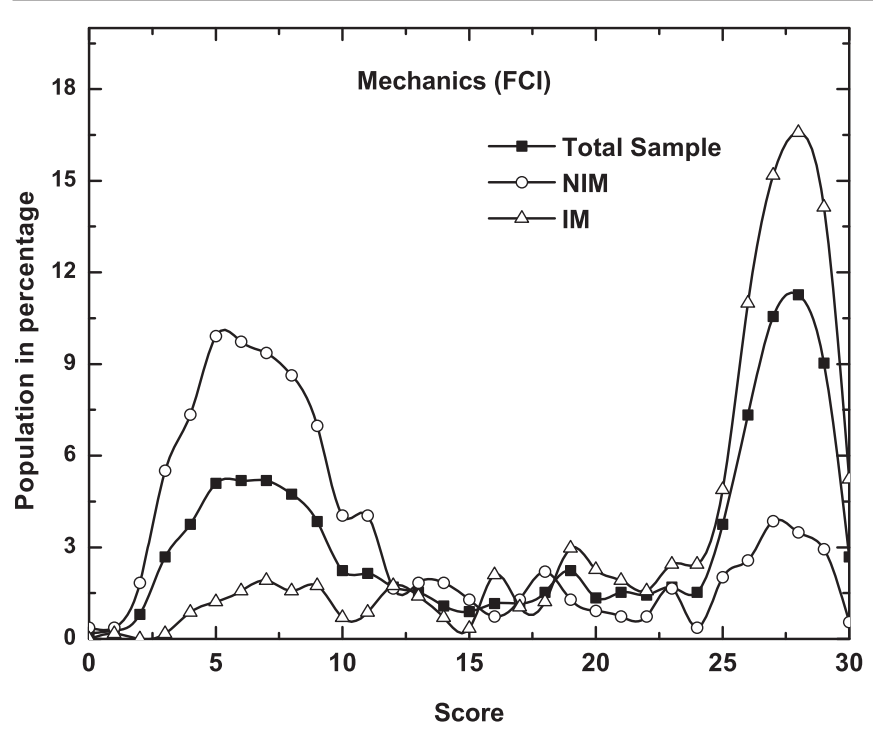

FIG. 1. Performance of Indian students in the FCI [19], a standardized test in mechanics consisting of 30 questions. The graph is first plotted for the whole sample and then separately for the NIM and the IM. Note the bimodality in the plot for the whole sample.

similar levels of instruction on the respective topics. The LCTSR average of the Indian students is slightly below that of both the American $(74.2 \pm 18.0)$ and the Chinese $(74.7 \pm 15.8)$. These averages, however, camouflage a disturbing underlying phenomenon which we shall now discuss.

Figure 1 depicts the distribution of the scores with population percentage in the FCI. The graph is plotted for the total sample and then separately for the NIM and IM mode by dividing the sample accordingly. As can be seen there exists a bimodality for the total sample, with the first peak centered around the chance score $6(20 \%)$. There is a flat region and the second peak runs from a score of 24 to the maximum (i.e., $80 \%$ to $100 \%$ ). Overlapping this graph with the plot for the NIM group reveals that the lower peak consists largely of students from the nonintegrated mode. On the other hand, a majority of the students falling under the second peak is from the integrated mode, as revealed by the IM plot. This result is consistent with the average scores for NIM and IM shown in Table I. The pattern of graph for CSEM as depicted in the Fig. 2 reveals a similar bimodality for the total sample. Once again the lower and the higher peaks can be attributed broadly to NIM amd IM, respectively, as shown in the plots. The same pattern was observed for the test on rotational kinematics developed by us as well, which is not depicted herein $[16,17]$. Better performance by students in the integrated mode is consistent with our observations of the students who qualify for the final phase of selection to represent India in the international olympiads (Homi Bhabha Centre is the nodal center for science olympiads in the country). In Fig. 3 we plot the distribution of scores for the LCTSR. Unlike the

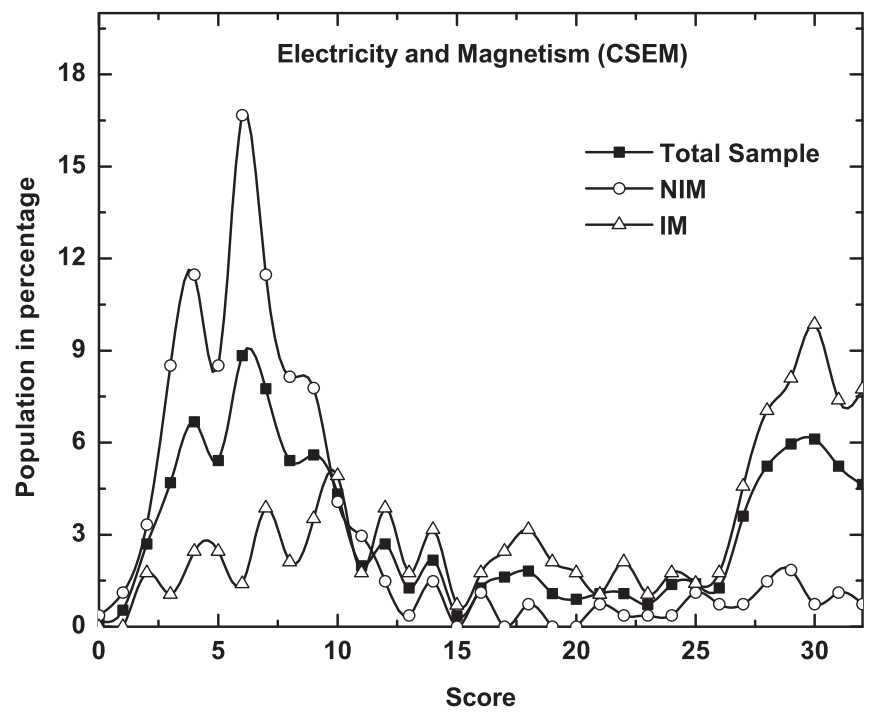

FIG. 2. Performance of Indian students in the CSEM [21], a standardized test in electricity and magnetism consisting of 32 questions. The graph is first plotted for the whole sample and then separately for the NIM and the IM. Note the bimodality in the plot for the whole sample.

physics tests, the shape of the graph for LCTSR is unimodal for the total sample with the percentage of students increasing with the score.

\section{CONCLUDING REMARKS}

Our findings are at variance with the American and the Chinese as far as physics tests are concerned. It is unimodal for both the countries while a bimodality exists for India.

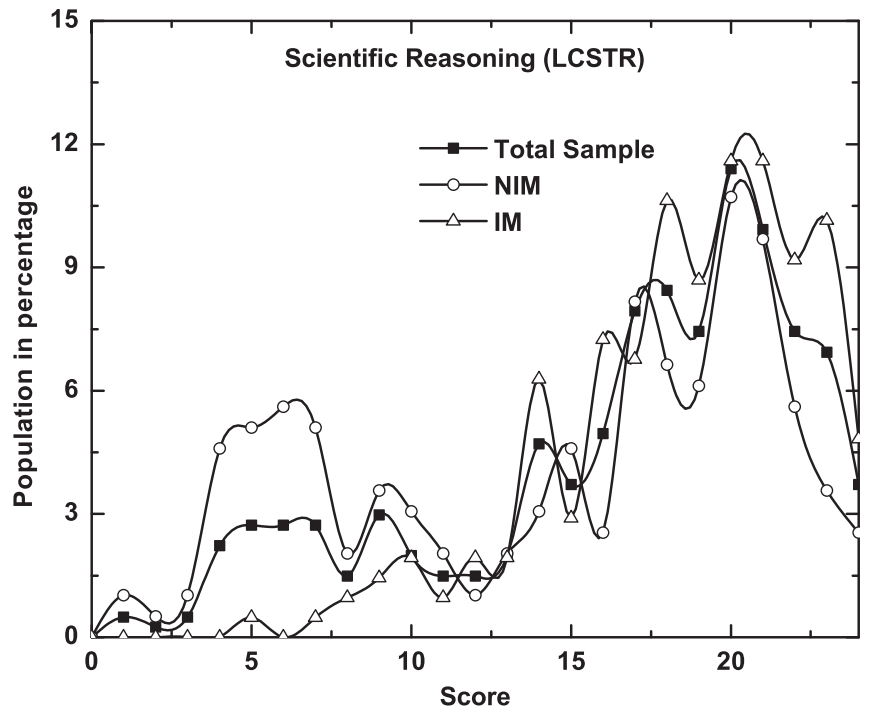

FIG. 3. Performance of Indian students in the LCTSR [23], a standardized test in general scientific reasoning consisting of 24 questions. The graph is first plotted for the whole sample and then separately for the NIM and the IM. Note the absence of bimodality. 
The finding regarding scientific reasoning is, however, similar. This validates the result of Bao et al. that content knowledge does not necessarily impact general scientific reasoning [1,2]. The lower peak indicates deficient understanding while the higher bracket is suggestive of conceptual understanding and problem solving skills. However, we do not advocate the teaching-learning styles, even of the integrated mode. This is because often hands-on activities and laboratory work are neglected by the private coaching centers. Disproportionate emphasis on drill and practice is another deficit.

The fact that the lower and higher peaks can be broadly attributed to NIM and IM, respectively, has an underlying economic connotation. The integrated mode can afford better infrastructure and attract competent teachers compared to the nonintegrated mode. Our study thus corroborates the finding that private coaching centers promote social inequality [14]. The Asian Development Bank report indicates the influence of private coaching centers in China as well [14]. The contentious nature of this parallel education system in Asian countries should be a subject of further discussion. Perhaps the superior performance of Chinese and Indian students are not without a price.

Economic status and the resulting affordability of preparations as a factor in explaining the performance difference among students is insightful, though not surprising. Strength of preparation has been found to be among the most significant contributing factors in explaining gender gap in concept inventory scores [25]. However, considering the complex interplay of multiple socioeconomic and cultural factors we should be wary of simplistic overstatements of the role of any single factor in explaining performance differences. With regard to our sample we think that the role of language (proficiency in English), schooling condition, parental education, and income warrant further investigation. These factors have proved to be significant in explaining performance gaps in relatable contexts elsewhere [26-28].

As a concluding remark, science education research which is currently a nascent area of academics in India needs to be catapulted into the mainstream to study and address the above mentioned issues systematically. In India work in this field has been scant and sporadic [29]. An initiative specifically relevant to the present study and worth mentioning is that popular concept inventories are getting translated to Indian languages, particularly Hindi (spoken by nearly 500 million people). The Hindi translation of FCI is now available on Physport [30].

\section{ACKNOWLEDGMENTS}

We are grateful to the referees for their valuable comments. This work was supported by the Science Olympiad and the National Initiative on Undergraduate Sciences (NIUS) undertaken by Homi Bhabha Centre for Science Education-Tata Institute of Fundamental Research (HBCSE-TIFR), Mumbai, India. We thank Vashti Sawtelle, Paula Heron, and Peter Shaffer for useful discussions.
[1] L. Bao et al., Learning and Scientific Reasoning, Science 323, 586 (2009).

[2] L. Bao, K. Fang, T. Cai, J. Wang, L. Yang, L. Cui, J. Han, L. Ding, and Y. Luo, Learning of content knowledge and development of scientific reasoning ability: A cross culture comparison, Am. J. Phys. 77, 1118 (2009).

[3] D. Halliday, R. Resnick, and J. Walker, Fundamentals of Physics (John Wiley and Sons, Singapore, 2001).

[4] H. D. Young and R. A. Freedman, University Physics (Pearson Education, New Delhi, 2004).

[5] D. C. Giancoli, Physics (Pearson Education, New Jersey, 2005).

[6] NCERT, Physics-Part I and II (National Council for Educational Research and Training, New Delhi, 2006).

[7] H. C. Verma, Concepts of Physics-Vol. I and II (Bharati Bhavan, New Delhi, 2011).

[8] K. S. J., An unwelcome export success, Nature (London) 366, 618 (1993).

[9] P. Bagla, Indian schools cash in on silicon valley wealth, Science 288, 794 (2000).

[10] A. Nayar, Developing World: Educating India, Nature (London) 472, 24 (2011).
[11] CBS News report, 60 Minutes -Imported from India, first aired 2 March, 2003, http://www.cbsnews.com/830118560_162-559476.html.

[12] T. L. Friedman, The World Is Flat (Penguin, India, 2007).

[13] P. Agarwal, Indian Higher Education: Envisioning the Future (Sage Publications, New Delhi, 2009).

[14] M. Bray and C. Lykins, Shadow education: Private Supplementary Tutoring and Its Implications for Policy Makers in Asia (Asian Development Bank, Philippines, 2012).

[15] V. A. Singh and P. Pathak, The role of friction in rolling bodies: Testing students' conceptions, evaluating educational system and testing the test, Proceedings epiSTEME2: International conference to review research on Science, Technology and Mathematics Education, edited by C. Natarajan and B. Choksi (McMillan, India, 2007), pp. 114-115.

[16] K. K. Mashood and V. A. Singh, Rotational kinematics of a particle in rectilinear motion: Perceptions and pitfalls, Am. J. Phys. 80, 720 (2012).

[17] K. K. Mashood and V. A. Singh, An inventory on rotational kinematics of a particle, Eur. J. Phys. 33, 1301 (2012). 
[18] JEE-2012 Report-Indian Institute of Technology, Kanpur, 2019, http://iitk.ac.in/new/data/jee-report/JEE-2012Report .pdf.

[19] D. Hestenes, M. Wells, and G. Swackhammer, Force Concept Inventory, Phys. Teach. 30, 141 (1992). We administered the 1995 version.

[20] J. I.Yasuda, U. Haruko, and N. Hideo, Validating a japanese version of the Force Concept Inventory, Lat. Am. J. Phys. Educ. 1, 89 (2012).

[21] D. Maloney, T. L. O'Kuma, C. J. Hieggelke, and A. V. Heuvelen, Surveying students conceptual knowledge of electricity and magnetism, Am. J. Phys. 69, S12 (2001).

[22] M. Planinic, Assessment of difficulties of some conceptual areas from electricity and magnetism using the Conceptual Survey of Electricity and Magnetism, Am. J. Phys. 74, 1143 (2006).

[23] A. E. Lawson, The development and validation of a classroom test of formal reasoning, J. Res. Sci. Teach. 15, 11 (1978). We administered the revised version (2000).

[24] L. Ding, R. Chabay, B. Sherwood, and R. Beichner, Evaluating an electricity and magnetism assessment tool:
Brief electricity and magnetism assessment, Phys. Rev. ST Phys. Educ. Res. 2, 010105 (2006).

[25] A. Madsen, S. B. McKagan, and E. C. Sayre, Gender gap on concept inventories in physics: What is consistent, what is inconsistent, and what factors influence the gap?, Phys. Rev. ST Phys. Educ. Res. 9, 020121 (2013).

[26] J. Lee, Racial and ethnic achievement gap trends: Reversing the progress toward equity?, Educ. Res. 31, 3 (2002).

[27] W. F. Tate, Race-ethnicity, SES, gender, and language proficiency trends in mathematics achievement: An update, J. Res. Math. Educ. 28, 652 (1997).

[28] F. C. Curran and J. Kitchin, Why are the early elementary race/ethnicity test score gaps in science larger than those in reading or mathematics? National evidence on the importance of language and immigration context in explaining the gap in gaps, Sci. Educ., DOI: 10.1002/sce.21491 (2018).

[29] epiSTEME-7: International Conference to Review Research on Science, Technology and Mathematics Education, Conference Proceedings, edited by S. Ladage and S. Narvekar (CinnamonTeal, India, 2018).

[30] H. K. Pandey and V. Singh, Hindi Translation of FCI, 2019, https://www.physport.org/assessments. 